\title{
Participação Política e o Golpe de 1964
}

Eduardo Zayat Chammas, Fernando Augusto Fróio Monteiro, Fernando Sarti Ferreira, Lucas Monteiro de Oliveira

\section{Resumo}

Neste artigo, discutimos a participação política de setores da sociedade brasileira através de associações de classes às vésperas do golpe civil-militar de I964. Usamos como referência os autores discutidos pelo grupo de estudos Fascismo e Ditadura.

Palavras-chave: golpe de I964, participação política, IPES/IBAD, nacionalreformismo, bloco multinacional associado. 


\section{Introdução}

Este artigo é resultado de recentes leituras e discussões do grupo de estudos Fascismo e Ditadura ${ }^{I}$. Tendo realizado estudos sobre o golpe civil-militar de I $964^{2}$, a partir de uma opção teórica baseada na leitura de autores marxistas, procuraremos desenvolver a questão da participação política no governo João Goulart (I96I-I964), fator essencial para a compreensão do golpe. Nosso objetivo não é encerrar o debate sobre o tema, mas contribuirmos com as reflexões do grupo.

Consideramos importante, primeiramente, explicitar o que entendemos por participação política neste estudo e justificar o por que do recorte escolhido. O termo permite inúmeras definições, mas o que temos em vista é a forma como setores sociais civis, não ligados institucionalmente ao Estado, inseriramse no debate e na atuação política. Ou seja, não temos por objeto a ação política na esfera estatal, que envolve senadores, presidente, prefeitos, vereadores, governadores, ministros. Interessa-nos aqui a participação política através de organismos de classe específicos e entidades da sociedade civil organizada como sindicatos, institutos, associações e movimentos sociais. Sabemos que muitas vezes há uma forte interligação entre ambas as esferas, mas não é este o enfoque principal deste artigo.

O período escolhido foi marcado por um intenso envolvimento de diversas camadas da população na vida política brasileira ${ }^{3}$; conseqüentemente, foi também marcado por um forte acirramento das tensões sociais, políticas e ideológicas. $\mathrm{O}$ desfecho deste período, o golpe civil-militar, indica-nos caminhos para pensar os limites da participação política dentro de um regime democrático burguês ${ }^{4}$.

I O grupo de estudos Fascismo e Ditadura é um dos subgrupos do PET história da USP, e tem desenvolvido pesquisas sobre os regimes autoritários lendo algumas obras e alguns trechos selecionados sobre o tema. Dentre as leituras até agora realizadas encontram-se: René Armand Dreifuss. 1964: A conquista do Estado. Petrópolis: Editora Vozes, I987. Caio Navarro de Toledo. O governo Goulart e o golpe de 64. São Paulo: Editora Brasiliense, I982. Florestan Fernandes. "O modelo autocrático-burguês de transformação capitalista”. In: A revolução burguesa no Brasil. Rio de Janeiro: Zahar Editores, I98I.

2 Como deverá ficar claro ao longo deste artigo, a participação dos setores civis da sociedade foi fundamental para a realização do golpe - daí o uso do conceito golpe civil-militar. Ao contrário do que se costuma dizer, o golpe não teve um caráter predominantemente militar.

3 Para tal afirmação, nos baseamos em G. N. Toledo, op. cit., cap. "A politização da sociedade - esquerda e direita se mobilizam”.

4 Esta reflexão tem por base a discussão realizada por F. Fernandes, op. cit., cap. "O modelo autocráticoburguês de transformação capitalista”. 
Cabe ressaltar que para nós é fundamental debruçar-se sobre o passado para compreender suas causas, rupturas e permanências. Como diz Theodor Adorno, "o passado só estará plenamente elaborado no instante em que estiverem eliminadas as causas do que passou. $\mathrm{O}$ encantamento do passado pôde se manter até hoje unicamente porque continuam existindo suas causas" ${ }^{5}$. Ao estudarmos este período, acreditamos que contribuímos para a reflexão sobre os limites de atuação dentro da democracia burguesa na qual estamos inseridos, dado o fato de que os instrumentos e agentes de dominação presentes em I964 ainda exercem forte influência na sociedade brasileira.

\section{A Queda de Jânio e a Crise do Populismo}

O momento anterior ao golpe era de crise do modelo de dominação populista que vigorava na política brasileira desde I945, segundo René A. Dreifuss ${ }^{6}$. Isto se dava tanto por conta da insatisfação do bloco multinacional associado (a aliança do empresariado nacional e internacional) quanto pela demanda de distribuição de renda das classes populares; o governo de Jânio Quadros foi a última tentativa de manter o pacto populista, mas não obteve êxito. O populismo udenista, aliança das forças conservadoras com o pequeno PDG de Jânio Quadros, representava o projeto político da UDN (União Democrática Nacional) e da ESG (Escola Superior de Guerra), no qual se expressavam os grupos econômicos em ascensão. Existia possibilidade de realização de um governo que atendesse aos interesses empresariais "contra herdeiros do getulismo, contra a esquerda e a demagogia governamental" 7 , nas palavras da ESG.

De um lado, encontravam-se setores populares que demandavam o crescimento distributivo da economia, o que não figurava no horizonte do populismo (principalmente em sua versão udenista). As reivindicações mais avançadas da classe trabalhadora levavam a uma ruptura da forma de dominação e controle tradicionais. Os sindicatos não eram mais inteiramente subordinados ao governo como haviam sido por anos, desde a construção de uma estrutura de cooptação e repressão na ditadura de Getúlio. Com tal mudança, tornava-se mais evidente o conflito de classes, até então maquiado pelo consenso populista.

5 Theodor W. Adorno. "A importância de elaborar o Passado". In: Educação e Emancipação. São Paulo: Paz e Terra, I995.

6 R. A. Dreifuss, op. cit., p. I25 e ss.

7 idem, ib. p. 128

Humanidades em Diálogo, vol i, n. I, nOV. 2007 
Do outro lado, o bloco multinacional associado não possuía, dentro do modelo populista, um poder de participação política proporcional à parte que detinha da economia ${ }^{8}$. O fato de concentrar os recursos financeiros e poder econômico no país daria, dentro da lógica capitalista, maior espaço para direcionar as políticas a serem adotadas pelo poder público. A manutenção do consenso populista dependia do balanço entre as propostas do capital internacional e da burguesia nacional e as de outros setores da sociedade. Um regime pluralista não conseguia levar a cabo os interesses diretos do bloco multinacional associado, uma vez que "tal sistema, apesar de restrito, era aberto a interesses e pressões conflitantes que, segundo a política comum do populismo, deviam ser parcialmente conciliados" 9 .

A aposta do bloco multinacional no populismo udenista foi frustrada. Jânio, apesar de trazer para dentro do governo elementos do bloco, enfrentou dificuldades econômicas que, somadas ao projeto conservador da UDN, demonstraram a impossibilidade de realizar o crescimento distributivo prometido à população. A UDN chegou ao executivo pela demagogia e apelo popular do excêntrico líder do PDC, o que dificultava a manutenção da conciliação populista.

Isso possibilitou a ascensão de um executivo nacional-reformista encabeçado por João Goulart, o que abriu mais espaço para a pressão das classes populares, que apresentaram um programa de reformas de base (reforma administrativa, reforma fiscal, reforma agrária e reforma bancária). Nas palavras de João Goulart, almejavam a transformação de "um capitalismo selvagem, em um mais humano e patriótico"ı。 . O aumento das pressões populares forçou a unidade dentro da classe burguesa; a distribuição de riqueza desejada com tais reformas ameaçava diminuir as relações de super-exploração, fundamentais para o capitalismo brasileiro ${ }^{\mathrm{II}}$. A ação política das classes populares e das elites será analisada mais adiante neste artigo.

Ainda para Dreifuss, a crise do populismo se inseria em um contexto de deslocamento ideológico entre representantes e representados, ou seja, as pessoas não reconheciam seus interesses nas posturas adotadas pela classe po-

8 R. A. Dreifuss, op. cit., p. I38.

9 idem, p. I29.

IO G. N. de Toledo, op. cit., p. I3 e ss.

II R. A. Dreifuss, op. cit., e Caio Prado Jr. A revolução brasileira. São Paulo: Editora Brasiliense, I966.

I2 Na política brasileira, não encontramos, salvo em raros momentos, uma identificação de programa ideológico entre representantes e representados. Apesar disto, temos que admitir que os grandes partidos tradicionais perderam espaço entre I945 e I962 para partidos de centro usualmente mais fisiológicos. R. A. Dreifuss, op. cit., p. I36 e ss. 
lítica. Não existia uma identificação programática entre os partidos políticos e seus eleitores, o que tornava possível uma saída autoritária. Mesmo dentro dos partidos não havia identidade entre os eleitos e o projeto do partido, e serve como ilustração deste cenário o fato de ser comum, após as eleições, a troca de partidos entre deputados ${ }^{12}$.

\section{As Classes Populares se Mobilizam}

A mobilização política entre I96I e I964 envolveu diversos setores da sociedade de forma mais intensa do que a vista até então. As classes populares envolveram-se tanto no campo quanto na cidade em lutas econômicas e políticas.

$\mathrm{Na}$ cidade, a atividade sindical ganhou força: enquanto no período JK foram realizadas $I 77$ greves, no período aqui estudado foram $435^{13}$. Esta mobilização se materializa em uma central sindical que agregava diversas categorias profissionais (a Central Geral dos Trabalhadores - GGT), o que era proibido pela legislação brasileira. As ações grevistas e reivindicatórias convocadas pela GGT unificavam diversos setores da classe trabalhadora. A burguesia brasileira encarava a CGT como o "quarto poder" que visava tornar o Brasil comunista, e ficava assustada com o diálogo estabelecido entre o presidente João Goulart e a central sindical ${ }^{\mathrm{I4}}$.

Ideologicamente, a GGT era hegemonizada pelo Partido Comunista Brasileiro ( $\mathrm{PCB}$ ), que propagava um ideal nacional-reformista, em que a partir da aliança com os ditos setores progressistas da burguesia se conseguiria estabelecer um programa de desenvolvimento nacional para o Brasil aliado às reformas sociais. Tal posicionamento justificava o apoio da GGT às iniciativas do governo Jango ${ }^{15}$. A idéia da direção da CGT era que, através de greves políticas pelas reformas de base, se conseguiria pressionar o congresso a aprovar as medidas nacionalistas do executivo. Podemos então identificar que as greves tinham um forte caráter político, e que não se restringiam a reivindicações por melhores salários, mas lutavam por um determinado projeto para o Brasil.

Uma análise mais aprofundada das mobilizações feitas pela CGT nos mostra que a força atribuída à central era maior que a sua real inserção na classe

I3 C. N. de Toledo, op. cit. p. 74 .

I4 Esse diálogo ocorria principalmente em períodos de greve geral.

I5 idem, ib. 
trabalhadora. Devemos ressaltar que a maior parte dos setores mobilizados nas greves pertencia ao funcionalismo público; não estavam fortemente mobilizados os trabalhadores industriais de São Paulo (onde se concentrava boa parte do proletariado brasileiro $)^{\mathrm{I} 6}$. Além disso, não existiu uma política de fortalecimento das bases sindicais: a preocupação exclusiva era a de pressionar o Congresso, deixando de lado a atuação direta dentro das empresas, no sentido de ampliar a organização dos trabalhadores ${ }^{17}$. Este distanciamento, segundo Caio Navarro de Toledo, explica porque o operariado assistiu de braços cruzados "à preparação e ao desfecho do golpe anti-popular e antioperário" ${ }^{18}$.

A mobilização das classes populares deu-se também no campo, onde tiveram, inicialmente, um papel destacado as Ligas Camponesas, que tinham como principal reivindicação uma reforma agrária radical. Nas palavras do líder Francisco Julião, o inimigo era o latifundiário que tirava a terra do camponês, portanto, a reivindicação devia ser pela divisão da propriedade da terra. Os sindicatos de trabalhadores rurais, unidos inicialmente pela idéia de que no campo predominavam relações capitalistas, consideravam que era necessário lutar por melhores condições de trabalho. Rapidamente abandonam esta concepção e, seguindo a linha do $\mathrm{PGB}$, adotam como lema a reivindicação pela reforma agrária e a luta pela terra.

Esta linha política de atuação é duramente criticada por Caio Prado Jr. em seu A revolução brasileira, em que sustenta que o campo brasileiro é estruturado de forma capitalista, e portanto a atuação nele deve ser no sentido de melhoria das condições de trabalho do proletariado rural. Para ele, ao contrário do que pensa a direção do $\mathrm{PGB}$, o espaço rural brasileiro nunca viveu um sistema feudal: não predomina uma relação camponesa de posse da terra. Assim, organizar-se em torno da luta pela posse da terra não faz sentido no campo brasileiro, estruturado desde o início com mão-de-obra intensiva, voltado para a produção em larga escala para importação. Para Caio Prado, a luta social só avançaria se fosse por melhores condições de trabalho ${ }^{19}$.

I6 G. N. de Toledo, op. cit. p. 75 e 76.

I7 idem, ib.

I8 idem, ib.

Ig Caio Prado Jr. op. cit. Cabe ressalvar aqui que no tempo em que Caio Prado Jr. escreveu seu A revolução brasileira, ainda não havia ocorrido o massivo êxodo rural no campo e que o panorama traçado por ele não serve, e não teria como servir, para entender os movimentos rurais surgidos na década de 80 como o MST (Movimento dos Trabalhadores Rurais Sem Terra). 
Aliado a estas mobilizações das classes populares, encontrava-se o movimento estudantil, que tinha como foco específico a reforma universitária. Esta se encontrava ideologicamente próxima do pacote de reformas de base, que deveria constituir-se como um projeto nacional para o Brasil. Por conta deste entendimento, vemos a UNE engajando-se na luta pela reforma agrária, contra o latifúndio e contra o imperialismo.

É possível afirmar que as formas predominantes de mobilização da esquerda às vésperas do golpe, fossem elas ligadas à GGT, às Ligas Camponesas, ao $\mathrm{PGB}$ ou à UNE, se aproximavam todas de um projeto nacional-reformista, influenciado em certa medida pelo pensamento cepalino ${ }^{20}$ (que entendia ser necessário passar por um amplo processo de industrialização elaborado a partir do planejamento estatal para romper com o subdesenvolvimento): havia uma perspectiva anti imperialista de um processo capitaneado pelo Estado com o objetivo de superar o atraso, diminuir a pobreza e garantir uma melhor distribuição de renda. Para isso, era necessário forjar um pacto nacional em prol do desenvolvimento e da soberania. Não se tratava de romper imediatamente com o capitalismo; era necessário melhorar o patamar de bem-estar social da população através de algumas reformas e do desenvolvimento econômico - objetivos que só seriam alcançados através de um projeto nacional. De qualquer forma, mesmo sem propor uma transformação radical, o pensamento nacional-reformista mexia com interesses fundamentais das burguesias das potências centrais do capitalismo e da própria burguesia nacional.

Notamos aqui que de fato existiu uma maior mobilização das forças populares durante o governo João Goulart: a atuação destas dava-se no sentido de pressionar o poder público para conquistar reformas na tentativa de construir o projeto nacional-reformista. Porém, a força de mobilização encontrava-se mais nos discursos exaltados dos dirigentes do que introjetada na classe trabalhadora.

20 A GePAl (Comissão Econômica para a América Latina), vinculada à ONU, nasce no final da década de I940 - quando se vivia um momento de crise do pensamento liberal clássico - com o objetivo de promover o desenvolvimento econômico do continente latino-americano. Em meio à crise do liberalismo, um dos pilares do pensamento cepalino torna-se a discussão sobre o papel do Estado, fortemente influenciada pelo pensamento keynesiano e marcada por uma tentativa de interpretar a crise do capitalismo liberal a partir da periferia. A importância da CEPAL nos anos I950 e I960 é tamanha que dois de seus principais colaboradores - o argentino Raúl Prebisch e o brasileiro Celso Furtado - alcançaram papel de destaque na discussão teórica sobre a economia da América Latina e na formulação de políticas públicas para o desenvolvimento latinoamericano. Celso Furtado chegou a ser ministro do Planejamento no governo João Goulart. 


\section{A Mobilização do Bloco Multinacional Associado e a Preparação do Golpe}

Em resposta à intensa mobilização das classes populares e a um executivo disposto a realizar as reformas de base por elas reivindicadas, setores da burguesia nacional, sob liderança de grupos econômicos internacionais estabelecidos no país, reagiram com a efetivação de um projeto de ação ideológica, política e militar visando à tomada do Estado. Trata-se da criação do Instituto de Pesquisas e Estudos Sociais (IPES) ${ }^{21}$ e de uma prática de participação política baseada não somente na pressão sobre o governo, mas, principalmente, em um projeto golpista para o controle do Estado articulado pela elite econômica do país.

O IPES foi criado em fins de I96I por um grupo de empresários com o intuito de estimular em todo o país uma reação empresarial ao que consideravam uma "tendência esquerdista da vida política" ${ }^{22}$, e logo se uniu ao IBAD (Instituto Brasileiro de Ação Democrática, criado na década de I950), criando um poderoso complexo político-militar em que o IPES funcionava como centro estratégico de atuação e decisão, realizando de forma encoberta suas atividades, e o IBAD funcionava como instrumento público de atuação.

O complexo IPES/IBAD tinha por objetivos unir as classes burguesas em torno dos interesses corporativos do bloco multinacional associado, buscando a contribuição, mobilização e integração do maior número possível de pessoas para as atividades de forma a se tornarem efetivamente uma classe "para si" ${ }^{23}$; agir contra o governo nacional - reformista e contra o alinhamento das forças sociais que o apoiavam, preparando o cenário político nacional para uma intervenção militar; e dinamizar o processo de modernização capitalista conservadora. Para tanto, consideravam necessário o exercício de uma "liderança política compatível com sua supremacia econômica" ${ }^{24}$, possibilitando readequar e reformular o Estado de acordo com seus interesses.

Os líderes do IPES eram em sua maioria empresários representantes de

2I Esta parte sobre a formação e atuação do IPES é baseada inteiramente na obra de R. A. Dreifuss, op. cit., principalmente nos cap. v, VI e VII.

22 idem, ib. p. I63.

$23 \mathrm{Ou}$ seja, que esses grupos atuem coletivamente num mesmo sentido e interesse tendo em vista seus objetivos enquanto classe social.

24 idem, ib. 
associações de classe ${ }^{25}$, mas também contava com militares ligados à Escola Superior de Guerra, dentre os quais o General Golbery do Couto e Silva, intelectuais alinhados aos interesses do bloco multinacional associado e membros do clero católico. Os trabalhos do complexo IPES/IBAD estavam centralizados nas unidades de São Paulo e Rio de Janeiro, mas contavam também com unidades em outras regiões e através de uma rede de articulação com associações classistas de outros estados e municípios estendiam suas ações por todo o território nacional. Os recursos financeiros provinham de industriais brasileiros e estrangeiros, bancos nacionais e transnacionais, grandes proprietários, companhias de segurança e de publicidade etc. Também havia contribuições através de fornecimento de equipamentos ou prestação de serviços (como transporte aéreo e hospedagem). 297 corporações estadunidenses deram apoio financeiro ao IPES, IOI empresas de outros países deram contribuição adicional ${ }^{26}$. Uma CPI foi criada para investigar a suspeita de corrupção eleitoral nas eleições de 1962 para o Congresso. O alvo da Comissão era o envolvimento ilegal do capital privado e estrangeiro nos assuntos políticos por via do complexo IPES/IBAD. O IBAD foi considerado culpado por corrupção eleitoral e foi fechado, o IPES foi absolvido com base no argumento de que não havia realizado nenhuma atividade incomum que infringisse seus objetivos publicamente declarados em sua carta de fundação 27.

As atividades de doutrinação ideológica do IPES dividiam-se entre as voltadas para toda a sociedade e as voltadas especificamente para as classes dominantes. Através da doutrinação geral, buscavam apresentar sua abordagem dos problemas políticos e econômicos do país tanto aos responsáveis pela tomada de decisões políticas quanto ao público em geral, na tentativa de criar um repúdio social aos objetivos do governo nacional-reformista, geralmente assimilando-o a uma suposta ameaça comunista que vinha contaminando setores de toda a sociedade e procurando dissimular os interesses específicos multinacionais associados entre um conjunto mais amplo de pressões provenientes dos mais diversos setores sociais.

A mídia tinha um papel preponderante nesse tipo de atividade. O IPES conseguiu impor seus interesses à opinião pública através de seu relacionamento

25 Como a FIESP (Federação das Indústrias do Estado de São Paulo), o GOnclap (Conselho Nacional de Classes Produtoras), a CNG (Confederação Nacional do Comércio), o SESI (Serviço Social da Indústria), o SENAC (Serviço Nacional de Aprendizagem Comercial) entre outros.

26 idem, ib. p. 206.

27 idem, ib. p. 207. 
com os grandes veículos de comunicação da época ${ }^{28}$. O controle que o complexo IPES/IBAD tinha sobre as principais agências de publicidade também exercia forte influência na linha editorial dos principais jornais, rádios e televisões. $\mathrm{O}$ complexo apoiava e garantia a publicação na imprensa de manifestos produzidos por associações e categorias funcionais e profissionais veiculados por todo o país com grande repercussão. Essa ação nos meios de comunicação envolvia desde uma torção dos fatos conforme os seus interesses até a simples publicação de mentiras. O Globo destacava-se por publicar "notícias" sem a divulgação do autor ou da fonte. Um notável exemplo, que teve grande repercussão, foi a "notícia" publicada de que a União Soviética imporia a instalação de um Gabinete Comunista no Brasil ${ }^{29}$.

O complexo IPES/IBAD também realizava atividades de doutrinação ideológica voltadas especificamente para as classes dominantes, visando moldar a consciência dessas classes e envolvê-las para a ação. Consolidava-se assim a posição política do bloco multinacional associado. Segundo Dreifuss, "tomava tal atitude, objetivando unir o emergente bloco de poder em torno de um programa específico de modernização econômica e conservadorismo sócio-político" ${ }^{30}$. O lema que expressava essa ação ideológica era "se você não abandona os seus negócios por uma hora hoje, amanhã não terá negócio algum para se preocupar" ${ }^{31}$. Essas ações envolviam atividades como a realização de palestras, simpósios, congressos e discussões, publicação de artigos, revistas, livros e filmes, sempre em torno das questões políticas nacionais pela ótica ipesiana.

Além das ações de doutrinação ideológica, o IPES realizava uma campanha política com o objetivo de manipular a opinião pública para transformar a classe média em massa de manobra, unir as forças sociais empresariais, bloquear as forças nacional-reformistas no Congresso e impedir a solidariedade das classes trabalhadoras. Suas atividades tinham por objetivo conduzir a situação política e social a um ponto de crise em que as forças armadas fossem conclamadas a intervir. O IPES agia politicamente no sindicalismo urbano e rural, no movimento estudantil, em movimentos urbanos da classe média que atuavam em defesa da "educação cívica" e da

28 Os Diários Associados - rede de jornais, rádio e televisão de Assis Chateaubriand, a Folha de S. Paulo - do grupo de Octávio Frias, associado ao IPES, o Estado de S. Paulo e o Jornal da Tarde - do grupo Mesquita, ligado ao IPES, a TV Record, a TV Paulista, o Jornal do Brasil, o Correio do Povo, O Globo e a Rádio Globo entre outros. idem. ib. p. 233.

29 idem. ib. p. 233.

30 idem. ib. p. 232.

3I idem, ib. p. 252. 
"democracia cristã" e também no Congresso Nacional através dos políticos ligados ao bloco multipartidário da ADP (Ação Democrática Parlamentar).

A intervenção no meio estudantil se deu pelo envolvimento em eleições com a formação de chapas anticomunistas, pelo financiamento de publicações, criação de entidades estudantis paralelas (como o MED - Movimento Estudantil Democrático, em oposição à UNE), fornecimento de bolsas de estudo e patrocínio de viagens para os EUA. Tinham a intenção de infiltrar elementos "democráticos" no movimento estudantil e conter a mobilização política à esquerda. No meio sindical, sua atuação se deu pelo financiamento de organizações de classe "democráticas" e anticomunistas, tendo exercido a Igreja Católica papel fundamental, através de sindicatos e associações cristãs. Em geral, essas entidades procuravam seduzir os filiados com serviço dentário e médico gratuito, bem como cursos especializantes, enfatizando a possibilidade individual de ascensão social dos trabalhadores, a função social da empresa privada e os perigos do "comunismo ateu". Se o IPES falhou em arregimentar completamente o movimento estudantil e o sindical, suas ações tiveram êxito em frear a influência da esquerda na sociedade, ganhando tempo para o momento da ação militar.

A maior vitória das atividades políticas e ideológicas do IPES/IBAD foi a conquista da classe média enquanto massa de manobra. Aos olhos das elites, a opinião pública era determinada pela vontade da classe média urbana ${ }^{22}$, sempre sujeita à forte influência dos meios de comunicação; enquanto a vontade e as manifestações das classes populares eram vistas como fruto da "infiltração da ideologia comunista"33. Além da campanha midiática, foram criados movimentos paralelos femininos, cristãos e de "educação cívica"; no geral, coordenados por membros de famílias de alto status social. O auge dos esforços dessas associações orientadas pelo IPES se deu no dia de São José, padroeiro das famílias, com a Marcha da Família com Deus pela Liberdade, que reuniu mais de quinhentas mil pessoas em São Paulo. A marcha foi organizada em oposição ao comício pelas reformas, realizado seis dias antes (na sexta-feira, I3 de março de I964) e que foi a última tentativa de Jango em meio à crise política de arregimentar apoio popular ao seu governo. A importância da marcha e da conquista da classe média em oposição ao nacional-reformismo foi de legitimar uma ação de intervenção militar. Era necessário demonstrar aos militares que a opinião pública era favorável à derrubada do governo para que estes agissem ${ }^{34}$. Menos de duas semanas depois da marcha, o golpe foi realizado.

32 Esse entendimento elitista do termo opinião pública permanece até os dias de hoje.

33 idem. ib. p. 29I.

34 idem. ib. p. 297 e 298. 
O IPES também exerceu influência fundamental no Congresso, agindo principalmente através da $\mathrm{ADP}^{35}$. A ADP apresentava anteprojetos de leis elaborados pelo IPES e que consideravam serem projetos técnicos em oposição aos projetos "demagógicos" dos "agitadores". Sua ação se dava no sentido de evitar que as reivindicações populares ganhassem espaço e de minar os projetos nacionalreformistas, forçando o Executivo a legislar por decretos e criando um clima de ingovernabilidade que apontava para soluções extra-constitucionais.

\section{Conclusão}

A intensa mobilização política de diferentes setores da sociedade, tanto à esquerda quanto à direita, que propunha um projeto político, social e econômico para o país, é algo peculiar do período estudado. Foi um momento de forte tensão política e ideológica em que a efetividade e a plenitude da democracia burguesa, tal e qual esta se apresentava, puderam ser testadas. É neste sentido que uma análise da participação política civil torna-se essencial.

Como vimos, a mobilização das classes populares tinha principalmente o aspecto de pressionar as esferas de decisão política em prol das reformas de base, ou seja, pressão pela efetivação das medidas de caráter nacional-reformista. Buscavam a realização de um projeto político voltado para o desenvolvimento endógeno do capitalismo nacional que amenizasse os antagonismos e as contradições sociais brasileiras historicamente determinadas - não havia a perspectiva de uma ruptura radical ou da tomada do poder. Contavam com o apoio do governo, na figura de João Goulart, ainda que sem maioria no Congresso. Era este o objetivo da maior parte das esquerdas, embora não fossem poucas as divergências entre elas, e embora o grau de apoio a Jango variasse bastante. É preciso, contudo, relativizar o grau de mobilização das classes populares, já que as lideranças políticas dos grupos sociais organizados, notadamente - mas não só - no sindicalismo, encontravam-se, em geral, em grande descolamento político de suas bases. Sua força política foi superestimada não só por eles próprios, mas também pelas classes dominantes mobilizadas, que potencializaram esse sentimento com o objetivo de arregimentar as classes médias para seu projeto. Isso ficou claro diante da grande falta de visão da esquerda da iminência do golpe e da parca resistência à sua efetivação. Embora em termos numéricos a

35 Reunia principalmente parlamentares do PSD e da UDN, e seus membros eram escolhidos mais por posicionamento ideológico do que por filiação partidária. 
mobilização das classes populares não fosse tão forte quanto se imaginava, a sua força e atuação política eram de grande visibilidade e influência.

A mobilização das elites teve como objetivo excluir do cenário político as forças nacional-reformistas, abrindo caminho para o desenvolvimento de uma modernização capitalista conservadora levada a cabo pelo bloco multinacional associado. Para tanto, era necessário não só a derrubada do presidente João Goulart como também o combate à "esquerdização" da sociedade e seu alinhamento ao projeto nacional-reformista. Toda a campanha de doutrinação ideológica geral movida pelo IPES foi feita no sentido de voltar a opinião pública contra o presidente para dar legitimidade à ação militar. As Forças Armadas só agiriam se fossem movidas pelo "clamor popular" ${ }^{6}$. Foi esse o significado da bem sucedida arregimentação das classes médias promovida pelo IPES através da campanha midiática e da atuação dos movimentos urbanos anti-comunistas. A atuação do complexo IPES/IBAD no sindicalismo urbano e rural e no movimento estudantil obteve relativo sucesso enquanto tática de contenção dessas forças sociais em torno do nacional-reformismo. Serviu para frear seu desenvolvimento e força política, mas não para criar um consenso de direita. A atuação do IPES logrou êxito na doutrinação ideológica específica das classes dominantes, de forma a criar uma unidade política em torno do projeto nacional do bloco multinacional associado, impelindo-os para o apoio e articulação da ação golpista.

O golpe civil-militar de I964 veio barrar a inserção das classes populares na vida política nacional, bem como derrubar as forças nacional-reformistas dos poderes executivo e legislativo, e efetivar o projeto político de modernização capitalista conservadora do bloco multinacional associado a partir de um Estado burguês autocrático. Neste sentido, vale ressaltar o que observa Florestan Fernandes ${ }^{37}$. O capitalismo em países subdesenvolvidos tem sua viabilidade garantida por meio de instrumentos políticos de dominação, sendo acentuado pela alta concentração de renda onde boa parte da riqueza é drenada para fora do país. Assim, ele conduz a uma sobrecarga dos instrumentos políticos já existentes e requer a criação de uma nova estrutura política para a transformação capitalista. A função do Estado burguês de contenção de qualquer possível ascensão das forças populares precisa ser adaptada para conter as novas formas de participação política. O golpe civil-militar de I964 fez-se necessário para a manutenção da dominação burguesa no Brasil ao garantir a

36 Um golpe de Estado só não foi levado a cabo em I96I para impedir a posse de Jango porque as forças armadas não foram impelidas a agir pela sociedade, segundo o General Golbery do Couto e Silva. 37 F. Fernandes. op. cit., cap. "O modelo autocrático-burguês de transformação capitalista”. 
continuidade da transformação capitalista por meio da repressão de qualquer tentativa de contestação da mesma.

A partir dessas reflexões, é possível notar que no momento em que os setores populares esboçaram uma participação política com agenda própria, mesmo que nos moldes da democracia burguesa, houve, para os setores dominantes, a necessidade de uma intervenção autoritária.

\section{Referências Bibliográficas}

Adorno, Theodor W. "A importância de elaborar o Passado". In: Educação e Emancipação. São Paulo: Paz e Terra, I995.

Dreifuss, René Armand. 1964: A conquista do Estado. Petrópolis: Editora Vozes, I987.

FERnANDEs, Florestan. "O modelo autocrático-burguês de transformação capitalista". In: A revolução burguesa no Brasil. Rio de Janeiro: Zahar Editores, I98I.

Prado Jr., Caio. A revolução brasileira. São Paulo: Editora Brasiliense, Ig66.

Toledo, Gaio Navarro de. O governo Goularte o golpe de 64. São Paulo: Editora Brasiliense, I982.

EDUARDO Zayat Chammas é graduando em história pela USP e bolsista pelo PET.

E-mail: educhammas@hotmail.com.

FERnANDo Augusto Fróio Monteiro é graduando em história pela USP e bolsista pelo PET.

E-mail: monteiro_f@yahoo.com.br.

FERNANDO Sarti Ferreira é graduando em história pela USP e bolsista pelo PET.

E-mail: fernandosartiferreira@yahoo.com.br.

LUCAS Monteiro de Oliveira é graduando em história pela USP e bolsista pelo PET.

E-mail:pixies@gmail.com. 